\section{Clinical significance of isolated macrocalcifications detected by ultrasonography}

\author{
Leehi Joo, Jung Hwan Baek
}

Department of Radiology and Research Institute of Radiology, Asan Medical Center, University of Ulsan College of Medicine, Seoul, Korea

We read with great interest the article published by Paik et al. entitled "CT features of thyroid nodules with isolated macrocalcifications detected by ultrasonography" in Ultrasonography [1]. The authors evaluated isolated macrocalcifications (IMs) in the thyroid gland using ultrasonography (US) and computed tomography (CT). They defined IMs as isolated, calcified thyroid nodules with complete posterior acoustic shadowing in which no solid component was obviously identified within the nodules on US [1]. Their concern about IMs was that previous studies have either not clearly defined IMs [2] or categorized them incorrectly (as rim or peripheral calcifications) [3,4]. Regarding this issue, the authors clearly showed the nature of IMs on CT. Among the $20 \mathrm{IMs}, 90 \%$ (18 of 20) showed central calcification and 10\% (2 of 20) showed peripheral calcifications. Therefore, the authors argued that thyroid nodules with IMs detected on US should not be classified as rim or peripheral calcifications. The risk of malignancy of IMs seems to be 10\%-20\% [5]. The classification of the US lexicon plays an important role in the risk stratification of thyroid nodules for malignancy [1]. IMs are categorized as intermediate suspicion nodules in the Korean Thyroid Imaging Reporting and Data System (K-TIRADS) [6] and as moderately suspicious nodules in the American College of Radiology Thyroid Imaging Reporting and Data System (ACR TI-RADS) [7]. However, this has not been specified in the risk stratification of thyroid nodules in other thyroid society guidelines [1].

We appreciate the valuable results shown by the authors in this study. The results are very interesting and clinically useful. However, we have several questions and comments. First, regarding terminology, the word "isolated" is not very intuitive. We suggest alternative terms, such as "totally calcified nodule" or "macrocalcified nodule without a solid component." However, we recognize that these terms might not fully represent the nature of IMs. Second, we are concerned about serial changes of IMs. As the authors noted that a completely calcified nodule might increase the risk of a nondiagnostic fine-needle aspiration (FNA) biopsy result, regular follow-ups are especially important. Third, as core-needle biopsy (CNB) has shown a higher diagnostic efficacy than FNA in thyroid nodules with IMs on US [8], we believe that the study would have been more meaningful if it had included pathologic results from CNB of these thyroid nodules. Finally, regarding the relatively high nondiagnostic and/or biopsy failure rate of IMs, the malignancy risk of IMs may be higher than has been previously reported. In conclusion, the findings of this study suggest that IMs are clinically significant. We appreciate these observations and propose the need to develop more intuitive terminology for IMs and to evaluate their serial changes on US.

ORCID: Leehi Joo: https://orcid.org/0000-0002-5527-0476; Jung Hwan Baek: https://orcid.org/0000-0003-0480-4754

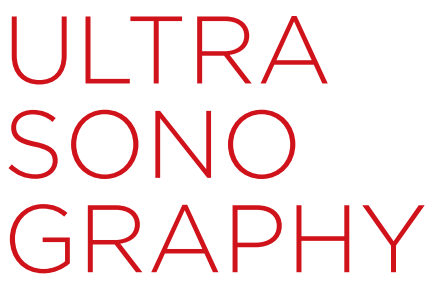

\section{LETTER}

https://doi.org/10.14366/usg.20075 pISSN: 2288-5919 • elSSN: 2288-5943 Ultrasonography 2020;39:407-408

Received: May 23, 2020

Revised: May 27, 2020

Accepted: June 8, 2020

Correspondence to: Jung Hwan Baek, MD, PhD, Department of Radiology and Research Institute of Radiology, Asan Medical Center, University of Ulsan College of Medicine, 88 Olympic-ro 43-gil, Songpa-gu, Seoul 05505, Korea

Tel. $+82-2-3010-4348$

Fax. +82-2-476-4719

E-mail: radbaek@naver.com

This is an Open Access article distributed under the terms of the Creative Commons Attribution NonCommercial License (http://creativecommons.org licenses/by-nc/4.0/) which permits unrestricted noncommercial use, distribution, and reproduction in any medium, provided the original work is properly cited.

Copyright (C) 2020 Korean Society of Ultrasound in Medicine (KSUM)

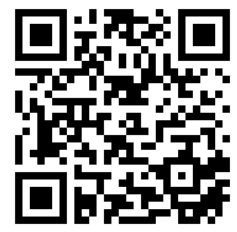

How to cite this article:

Joo L, Baek JH. Clinical significance of isolated macrocalcifications detected by ultrasonography. Ultrasonography. 2020 Oct;39(4):407-408. 


\section{Conflict of Interest}

No potential conflict of interest relevant to this article was reported.

\section{References}

1. Paik W, Na DG, Gwon HY, Kim J. CT features of thyroid nodules with isolated macrocalcifications detected by ultrasonography. Ultrasonography 2020;39:130-136.

2. Pompili GG, Tresoldi S, Ravelli A, Primolevo A, Di Leo G, Carrafiello $G$. Use of the ultrasound-based total malignancy score in the management of thyroid nodules. Ultrasonography 2018:37:315322.

3. Malhi HS, Velez E, Kazmierski B, Gulati M, Deurdulian C, Cen $S Y$, et al. Peripheral thyroid nodule calcifications on sonography: evaluation of malignant potential. AJR Am J Roentgenol 2019;213:672-675.

4. Yoon DY, Lee JW, Chang SK, Choi CS, Yun EJ, Seo YL, et al. Peripheral calcification in thyroid nodules: ultrasonographic features and prediction of malignancy. J Ultrasound Med 2007;26:1349-
1355.

5. Gwon HY, Na DG, Noh BJ, Paik W, Yoon SJ, Choi SJ, et al. Thyroid nodules with isolated macrocalcifications: malignancy risk of isolated macrocalcifications and postoperative risk stratification of malignant tumors manifesting as isolated macrocalcifications. Korean J Radiol 2020;21:605-613.

6. Shin JH, Baek JH, Chung J, Ha EJ, Kim JH, Lee YH, et al. Ultrasonography diagnosis and imaging-based management of thyroid nodules: revised Korean Society of Thyroid Radiology consensus statement and recommendations. Korean J Radiol 2016;17:370-395.

7. Tessler FN, Middleton WD, Grant EG, Hoang JK, Berland LL, Teefey SA, et al. ACR Thyroid Imaging, Reporting and Data System (TIRADS): white paper of the ACR TI-RADS Committee. J Am Coll Radiol 2017;14:587-595.

8. Son HM, Kim JH, Kim SC, Yoo RE, Bae JM, Seo H, et al. Distribution and malignancy risk of six categories of the pathology reporting system for thyroid core-needle biopsy in 1,216 consecutive thyroid nodules. Ultrasonography 2020;39:159-165. 